\title{
Sharkiyatiot
}

Cilt/Volume: 13, Sayı/Issue: 1 (Nisan/April 2021) Sayfa/Page: 353-366

\section{ZAZAKî DE BABETÊ HECEYAN}

\section{Ahmet KIRKAN}

Unîversîteya Mardin Artuklu, Beşê Ziwan û Edebîyatê Kurdkî, Mardin/Türkiye ahmetkirkan@gmail.com, https://orcid.org/0000-0003-3885-5218

\section{Article Types / Makale Türü}

Research Article / Araştırma Makalesi

\section{Received / Makale Geliş Tarihi}

$12 / 01 / 2021$

\section{Accepted / Kabul Tarihi}

20/04/2021

DOI: https://doi.org/10.26791/sarkiat.859667 


\section{ZAZAKÎ DE BABETÊ HECEYAN}

\section{KILMNUS}

Hece bi venganê vokalan reyde yeno sazkerdene û hûmarê heceyanê çekuyan goreyê hûmaranê vokalan yeno tesbîtkerdene. Heceyêke de tena yew heb vengo vokal zî eşkeno hece bibo. Na xebate de babetê heceyanê zazakî ameyê analîzkerdene. Heceyê zazakî goreyê taybetmendîyanê vokalan û konsonantan cîya şekilan a yenê tesnîfkerdene. Amancê na xebate goreyê vilabîyayîșê venganê vokal û konsonantan heceyanê zazakî dabeşkerdiş, analîzkerdiş; vengê ke çekuyanê zazakî de coda û onset de ca gênê tesbîtkerdiş, taybetmendîyanê nê heceyan tehlîlkerdiş o. Tayê heceyî goreyê krîteranê ziwannasîye sey heceya îdeale yenê namekerdene. Mîyanê xebate de babetê heceyan, goreyê na heceya îdeale ameyê îfadekerdene. Coda de û onset de bi kewtişê vokalan reyde gemînate konsonantî yênê meydan. Nê vengî zazakî de reya verêne na xebate de ameyê tesbîtkerdene. Heman şekil de tayê fekanê zazakî de xêncê di-konsonantan, dîftongî zî yenê meydan. Labelê nê her di tewirî zî sey heceyê musteqîlî nêhesibîyênê û hînterlandê nê heceyan goreyê heceyanê bînan zaf teng o. Xebate de gama ke babetê heceyan îzah bibê, nê faktoran kes eşkeno bi rehetî fehm bikero.

Kilîtçekuyî: Zazakî, Hece, Coda, Onset, Nucleus

\section{SYLLABLE TYPES IN ZAZAKI}

\section{ABSTRACT}

Syllables consist of vocal sounds, and the syllable numbers of words are determined by the number of vocal sounds. A syllable can contain only one vocal sound. They are important in the occurrence of features. In this study, syllable types in Zazaki were analyzed. The syllables in zazaki are classified in different ways according to the characteristics of vocal and consonant sounds. The aim of this study is to divide the syllables in Zazaki into sections according to the distribution of vocal and consonant sounds, to determine the sounds in the coda and onsets of words, to analyze the properties of these syllables. In the study, other syllables were expressed according to this ideal syllable. With the drop of vocal sounds in the coda and onsette, geminate consonant sounds come into play. These sounds were first identified in this study. In some mouths of the Zaza, diftonguas occur besides the geminant consonants. However, this type is not an independent syllable and the hinterland of these syllables is not wide. While explaining the syllable types in the study, we can easily identify these factors.

Keywords: Zazaki, Syllable, Coda, Onset, Nucleus 


\section{DESTPÊK}

\eng yan girseya vengan ke terefê organanê sazkerdoxanê vengî ra, reyêk ra vejîyênê sey hece yena namekerdene. Hece bi fonolojîyê ziwanan a têkildar a. Ziwan-yewîneyê ke heme ziwanan de ca gênê sazkerdişê heceyan de zî bi şekilêko aktîf wezîfe gênê (Karaağaç, 2013, 454). Nê ziwan-yewineyî sazkerdişê heceyî de sey vokal û konsonantî yenê dabeşkerdene. Artîkulasyonê venganê vokalan, cîya mintiqayanê fekî de û cîya hereketanê ziwanî reyde yeno meydan. Artîkulasyonê venganê vokalan de, organanê sazkerdoxan de tu astengêk nêyeno meydan. Vengê konsonantî zî cîya mintiqayanê fekî rê ginayişê hewayî reyde yenê meydan. Verê her hewa piroginayîş̂i, organanê sazkerdoxanê vengî de artîkulasyonê konsonantan yeno meydan. No vengo ke ameyo meydan seba ke hermeleyî ra bêro cîyakerdiş muhtacê vokalêk o.

Vengî sey vokal û konsonant yenê dabeşkerdiş û goreyê taybetmendîyanê akustîkî û artîkulasyonî yenê teqsîmkerdene (Karaağaç, 2013, 453-454). Heceyî reyêk ra fekê însanî ra vejîyênê û eslê xo de însanî bi heceyan a qalî kenê. (Aksan, 2015, 40). Gama ke ma vanê $A$-zad mek-teb ra ye-no. fonemê sey /a/,/z/, /d/ ûsn heceyan saz kenê û qalîkerdox meramê xo sayeyê heceyan îfade keno. Prosesê perwerdekerdişê ziwanî de metodê deduksîyonî de cumleyî çekuyan rê, çekuyî heceyan rê teqsîm benê. Nê heceyê neweyî îmkanê viraştişê çekuyanê neweyan awan kenê. Bi no şekil a, keso ke ziwanî bander beno heceyan ra eşkeno derbasê çekuyan bibo. Kes eşkeno vajo ke nê prosesî de hewce nêkeno ke heme çekuyê ziwanî bêrê banderkerdiş. Sayeyê îmkanê viraştişê çekuyan, keso ke ziwanî bander beno, eşkeno çekuyanê neweyan virazo.

Herçiqas her hece de hewce nêbo zî, vernî yan peynîya heceyan de konsonantî eşkenê ca bigîrê. Heceyan de vengo vokal sey nucleus (çekirdek) yeno namekerdene. Vengo konsonanto ke vernîya nucleusî de yo sey onset, konsonanto ke peynîya nucleusî de ca gêno sey coda yeno namekerdene. Heceyî hetê morfolojî ra hewce nîyo ke manayinî bê. Yanî heceyî eşkenê bêmana bê labelê morfemî ganî mana îfade bikerê. Qandê cû hece û morfemî yewbînî ra cîya yê. Heceyî bê venganê konsonantan yenê sazkerdiş labelê heceyî bê venganê vokalan nêyenê sazkerdene (Demirci, 2014, 82).

Heceyî goreyê vokalê peynî û goreyê vilabîyayîşê foneman di beşan rê teqsîm benê. Goreyê vokal û konsonantan rewşa dabeşkerdişî zafane weznê erûzî de yena şuxulnayene. Goreyê ney, weznê erûzî de heceyê ke bi vokalan reyde qedîyênê sey heceya akerdê (-wa, -ka, -lê ûsn), heceyê ke bi konsonantan reyde qedîyênê sey heceya girewtê (erd, bir, çendûsn) yenê namekerdene (Demirci, 2014, 82-83). Metnanê klasîkanê zazakî de akerde yan girewte bîyayîşê çekuyan tesîrê weznê metnî keno, nê semedî ra babetê hece metnanê klasîkan de zî muhîm o.

Vilabîyayîş û hûmarê fonemanê heceyî muhîm o. Yanî hece de çend hebî fonemî estê û nê fonemî mîyanê hece de çi şekil vilabîyê, seba tesbîtkerdişê babetê heceyî muhîm o. Kurdkî de 9 tewirî babetê heceyan estê. Seke vengê vokalî (herfa vengine) bi sembolê $V i ̂$ û vengê konsonantî (herfa bêvenge) bi sembolê $C i ̂$ ya yenê nîşandayene, heceyê ke kurdkî de ca gênê cêr ra ameyê ramojnayene. Tayê nimûneyî beno ke zazakî de çin bê. Seba babetanê heceyanê zazakî ma do nimûneyan dima ra bidê.

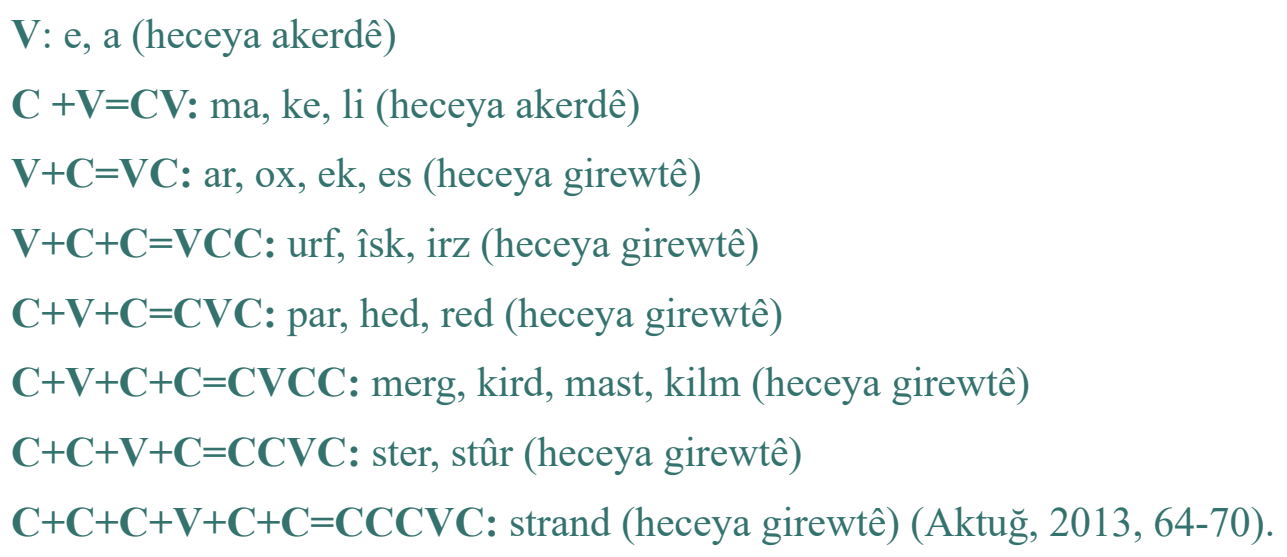

Her ziwanî de pergalê heceyan cîya yo. Saussure, heceyan de akerdişê fekî ra zêdêr, girewtişê fekî sey sînorî qebul keno (Saussure, 2014, 49-50). Goreyê tayê ziwannasan seba hece bîyayîşî tewr kêmî di hebî fonemî hewce yê (Aksan, 2015, 42). Labelê seba zazakî kes eşkeno vajo ke, yew fonem ra zî heceyî teşekul 
kenê. Seba heceyî şerto mecburî vokal o. Bê vokalan heceyî saz nêbenê. Vernî yan peynîya çekuye de dilete heceyî eşkenê ca bigîrê. Nê vengê diletî yan gemînate konsonantî zafane bi kewtişê venganê vokalan reyde yenê meydan. Hem zazakî de hem kurmanckî de nê tewir di hebî konsonantî vernî yan peynîya çekuye de ca gênê. Cêr ra nimûneyê nê konsonantan do bideyê.

\section{ZAZAKî DE HECEYî}

\subsection{ZAZAKî DE BABETÊ HECEYAN Û VILABÎYAYÎŞÊ VENGAN}

Çekuyî heceyan ra, heceyî herfan ra pê yenê. Yewineyo ke fonemî ra hîna derg û çekuye ra hîna kilm o, sey hece yeno namekerdene. Heceyan bi şekilêko kamil pênaskerdiş û nê mijarî hetê fonetîk û fonolojî ra îzahkerdiş asan nîyo (Crystal, 2008, 467). Kurdkî de seba heceyî kîte, birrge, hece ûsn nameyî yenê şuxulnayene. Zazakî de no mefhum bi hece ya yeno îfadekerdene. Hecekerdiş zî çekuyan goreyê heceyan yan goreyê teqsîmkerdişî îfade keno. Ziwanan goreyê heceyan teqsîmkerdiş de çend hebî teorîyê heceyan estê. Nê teorî heceyan goreyê meydan ameyîşî û wezîfeyî tedqîq kenê. Amancê nê teorîyan, pênasê heceyî ke heme ziwananê dinyayî de derbasdar o, tesbîtkerdiş o (Crystal, 2008, 467-468).

Heceyî tewr kêmî yew vokal ra saz benê. Nê venganê vokalan, vernî yan peynî ra konsonantî şênê taqîb bikerê. Kurdkî de goreyê derg yan kilm bîyayîşê vokalî, heceyî sey heceya derge yan heceya kilme yenê namekerdene. Nê vengî mîyanê çekuyan de goreyê qaydeyan rêze benê. Eke peynîya heceyan bi vengê konsonantî ya biqedîyo sey heceya girewtê, eke hece bi vengê vokalî ya biqedîyo sey heceya akerdê yena namekerdene. No rêzekerdiş sey fonotaksî yan fonotaktîk yeno namekerdene (Muhammed, bêtarîx, 158; Omar Mahmoud, 2016, 163).

Zazakî de her fonem eşkeno vernîya çekuye de ca bigîro. Mîsale kes eşkeno çekuyan amanc, beye, cane, çira, dewe, erdîşe, êleg, fehm, gonî, hewt, itya, însan, jehr, kar, lej, maye, neqiş, otogar, panc, qaşik, roşna, semed, şeqe, teşt, vatene, weçînayene, xeter, yew, zama bido. Zazakî de her fonem mîyanê çekuye yan heceyî de eşkenê heme ca de bibê. Tayê fonemî onsetê heceyan de zêde yenê şuxulnayene labelê hîn fonemî zî onset de tayê yenê şuxulnayene. Zazakî de heceyê ke konsonantan reyde dest pêkenê, heceyanê ke vokalan reyde dest pêkenê ra hîna zêde yê. Reyna zazakî de onset de konsonantê sey /b/, /d/, /h/, /m/, /p/ zêde yenê şuxulnayene labelê konsonantê sey /c/, /ç/, /f/, /j/, /v/ zêde nêyenê şuxulnayene. Heman şekil de zazakî de heceyê ke bi vokalanê /a/, /e/ dest pêkenê zêde yê labelê heceyê ke bi vokalanê /ê/, /i/, /î/, /o/, /û/ dest pêkenê kêm ê. Vurîyayîşê vengan, bedilîyayîşê vengan, kewtiş-zêdebîyayîşê vengan, çekuyê ke ziwananê xerîban ra derbasê zazakî bîyê ûsn mîyanê envanterê zazakî ra bivejîyê, heceyê ke bi vokalanê /û/, /i/ dest pêkenê zazakî de nêmanenê yan zaf kêmî manenê (Grûba Xebate ya Vateyî, 2019).

Heceyî goreyê pergalê CVCyî de (konsonant, vokal, konsonant), ke no pergalê heceyan îngilîzkî de esto; konsonanto verên onset yanî sere û destpêk, vokal nucleus yanî bizre û merkez, konsonanto dîyin coda yanî girewtiş, yenê namekerdene (Crystal, 2008, 468). Merkez û bingeyê heceyî nucleus yanî vengo vokal saz keno. Vokalî eşkenê xoserî heceyêke saz bikerê labelê konsonantî xoserî nêeşkenê heceyan saz bikerê. Seba sazkerdişê heceyan tu nêbo vokalêk hewce yo. Cêr ra elemanê ke hece de ca gênê goreyê pergalê CVCyî ameyê îzahkerdene.

\subsubsection{ONSET (SERE, BAŞLANGIÇ):}

Heceyan de qismê onsetî yew, di yan hîrê (tewr zêde û îstîsnaen) hebî konsonantan ra şêno bêro meydan. Kurdkî de her vengo konsonant eşkeno onset de ca bigîro. Kurdkî de eke onset de di hebî konsonantî ca bigîrê, na rewşe bi zêdekerdişê herfêka vokale reyde orte ra yena wedaritene (Muhammed, Bêtarîx, 48). Çekuyê ke ziwananê xerîban ra derbasê kurdkî bîyê, herçiqas vatiş de sey mîyanî-veng vokalan bigîrê zî nuştiş de nê vokalî nêyenê nuştene. Sey nimûne çekuyanê plan $>$ pîlan, traktor $>$ tiraktor ûsn de vatiş de herçiqas vokalî yenê vatene zî, nuştiş de nê vokalî nêyenê ramojnayene. 
Zazakî de gemînate konsonantî estê û nê konsonantî heceyan de onset de eşkenê ca bigîrê. Mabênê nê konsonantan de vokalê /i/yî esto labelê no veng hende şenik o, mîyanê nê konsonantan de vîndî bîyo. Dîyalekta kurmanckî de zî vindîbîyayîşê vokalê /i/yî esto. Nê çekuyan de heceya ewile nucleusê xo vîndî kena. No şekil a hece hîna şenik yena îfadekerdene. Hece rîdê kewtiş-vîndîbîyayîşê vokalî ra, girseyê konsonantan ra teşekul kena (Omar Mahmoud, 2016, 162). Vîndîbîyayîşê nucleusî û girseyê konsonantan ra pêameyîşê heceyî tim nêyeno meydan. Na rewşe ziwanê nuştekî ra zêdeyêr ziwanê fekkî de qewimîyena. Cêr ra zazakî de gemînate konsonantan ra tayê nimûneyî deyayê. Nê çekuyan de nucleus vîndî bîya, kewta. Tayê nimûneyan de bi vîndîbîyayîşê nucleusî ya hîrê hebî konsonantî pê pêya rêze bîyê.

Tablo 1: Zazakî de Onset de Gemînate Konsonantî

\begin{tabular}{|l|l|l|l|}
\hline br- & bira $>$ bra, birwey $>$ brwey & mş- & mişare $>$ mşare, mişewre $>$ mşewre \\
\hline bl- & bilo $>$ blo, bilusk $>$ blusk, blok & nm- & nimaj $>$ nmaj, nimite $>$ nmite \\
\hline bs- & bisilman $>$ bsilman & ps- & pispor $>$ pspor, pisîng $>$ psîng \\
\hline ct- & cite $>$ cte, cityer $>$ ctyer & ql- & qilancike $>$ qlancike \\
\hline cw- & ciwan $<$ cwan & sl- & silasnayene $>$ slasnayene \\
\hline çm- & çim $>$ çm & şk- & şikeft $>$ şkeft, şikitene $>$ şkitene \\
\hline çr- & çira $>$ çra, & şl- & şilabend $>$ şlabend \\
\hline dl- & dilop $>$ dlop, dilete $>$ dlete & şm- & şimitene $>$ şmitene \\
\hline dr- & dirnayene $>$ drnayene, dram & tf- & tifing $>$ tfing \\
\hline dw- & diwar $>$ dwar & tr- & tirafe $>$ trafe, tirê $>$ trê \\
\hline fr- & firine $>$ frine, firke $>$ frke & vl- & vilik $>$ vlik, \\
\hline gr- & gire $>$ gre, giran $>$ gran & ws- & wisar $>$ wsar \\
\hline kl- & kildar $>$ kldar, kilmî $>$ klmî, klasîk & xr- & xirap $>$ xrap, xirok $>$ xrok \\
\hline ln- & linge $>$ lnge, lince $>$ lnce & zw- & ziwan $>$ zwan, ziwa $>$ zwa \\
\hline
\end{tabular}

\subsubsection{NUCLEUS (MÎYANÎ, ÇEKIRDEK):}

Her hece de tena yew heb vokal beno û no vokal sey nucleus, bizre yan merkezî ya yeno namekerdene. Zazakî de heceyî eşkenê tena vokalan ra zî teşekul bikerê. Venganê vokalan ra /a/, /e/, /ê/, /î/, /û/, /o/ şênê xoserî heceyan saz bikerê. Vokalê bînî seba hece sazkerdişî ganî konsonantan a bêrê têhet (Muhammed, bêtarîx, 47). Yanî vokalê /i/, /u/ seba awankerdişê heceyan ganî konsonantan a pîya bibê.

\subsubsection{CODA (PEYNÎ, SON/KAPANIŞ):}

Mîyanê hece de konsonanto ke tewr peynî de ca gêno sey coda yan peynî name beno. Seba awanbîyayîşê heceyî, sey onsetî, bîyayîşê coda zî mecburî nîyo. Kurdkî de coda yew yan di hebî konsonantan ra şêna teşekul bikera. Çekuyê ke ziwananê bîyanîyan ra derbasê kurdkî bîyê de, sey çekuya tekstî, coda de hîrê hebî konsonantî zî şênê bibê. Zazakî de heme konsonantî eşkenê coda de ca bigîrê. Vengê konsonantê ke allofonê ci estê (aspîrate û unaspîrate) sey /ç/, /k/,/p/, /t/ tena aspîratê ci onset de eşkenê coda de ca bigîrê (Muhammed, Bêtarîx, 50-51).

Sey venganê onsetî, coda de zî yanî venganê girewtişî de zî ge gane vengê vokalî kewenê û peynîya heceyî de gemînate konsonantî yenê meydan. Xêncê hedîseyê vengan (vurîyayîş, ca bedilnayîş, zêde-kêm bîyayîş ûsn), çekuyê ke ziwananê xerîban (erebkî, fariskî, ziwananê ewropayî ûsn) ra derbasê zazakî bîyê, eke coda de ca bigîrê gemînate konsonantan anê meydan. Nê vengê di konsonantî peynîya çekuye de ca gênê (Muhammed, bêtarîx, 243-250; Omar Mahmoud, 2016, 163). Nê çekuyî zafane ziwanê xerîban ra û xususen zî erebkî ra derbasê zazakî bîyê. Cêr ra nimûneyê nê vengan deyayê. 
Tablo 2: Zazakî de Coda de Gemînate Konsonantî

\begin{tabular}{|c|c|c|c|c|c|}
\hline$-b b$ & rebb & -rç & qirç, mirç & $-\mathrm{xt}$ & bext, text, rext \\
\hline$-\mathrm{cm}$ & recm, hecm & $-r d$ & merd, mird, kurd & $-y f$ & heyf, keyf \\
\hline$-\mathrm{ft}$ & şikeft, zift & $-r f$ & herf, zerf & -yl & meyl, keyl \\
\hline -hl & tehl, dehl & $-\mathrm{rg}$ & merg, morg, org & $-\mathrm{yn}$ & deyn, beyn \\
\hline$-\mathrm{hn}$ & pehn, & $-\mathrm{rm}$ & germ, nerm & $-y r$ & seyr, deyr \\
\hline -hs & behs, nehs & $-r q$ & irq, xerq, berq & $-z q$ & rizq \\
\hline$-\mathrm{jn}$ & bejn & -rs & mars, ters, hêrs & -sk & mîsk \\
\hline$-\mathrm{ks}$ & eks & -rş & marş, tirş, kirş & -rk & terk, firk \\
\hline$-m d$ & hemd & $-r z$ & berz, derz & $-s t$ & sist, mest \\
\hline$-m p$ & kamp & $-\mathrm{rx}$ & çerx, berx & $-1 \mathrm{p}$ & çelp, telp \\
\hline$-n c$ & panc & -sk & kask, rîsk, dîsk & $-\mathrm{rt}$ & çirt, pirt \\
\hline -nd & çend, rind, bend & $-\mathrm{sl}$ & fesl, esl & $-w q$ & zewq, şewq \\
\hline$-n g$ & veng, ceng & -st & dest, test & -Wş & rewş, hewş \\
\hline$-n s$ & cins & -şk & meşk, rişk & $-w t$ & çewt, hewt, kewt \\
\hline$-\mathrm{ps}$ & heps & -şt & heşt, deşt & $-w Z$ & hewz \\
\hline$-q s$ & reqs & $-\mathrm{vd}$ & evd & -rc & merc, birc \\
\hline -qŞ & neqş & $-r b$ & herb, derb & $-q t$ & weqt \\
\hline$-\mathrm{sm}$ & resm & $-\mathrm{rn}$ & curn, kurn & & \\
\hline
\end{tabular}

\subsection{BABETÊ HECEYAN}

Zazakî de goreyê kombînasyonê venganê vokal û konsonantan 9 babetê heceyan ameyê meydan. Cêr ra nê babetî yew bi yew bi nimûneyan reyde ameyê îzahkerdene. Seba her babetê heceyan ferhenganê Grûba Xebate ya Vateyî ra nimûneyî deyayê. Mîyanê ziwanî de hetê şuxulnayîşî ra nîsbetê her babetê nê heceyan sey yewbînan nîyê.

\subsubsection{VOKAL (V)}

Nê heceyî tena yew vokalî ra pê yenê. Vokalanê zazakî ra /a/, /e/, /ê/, /o/, /û/, /î/ tena eşkenê heceyêke bibê. Yanî nê vengî tena bê zî, şênê sey heceyêk bêrê îfadekerdene. Vokalê bînî /u/, /i/ ancax bi konsonantan reyde eşkenê heceyan saz bikerê. Seba nê tewir heceyî cumleya Aye mi rê va $\hat{\boldsymbol{u}}$ dima şî. sey nimûne bideyo. Na cumle de vokalê ke qalind ameyê nuştene xoserî hece yê.

\subsubsection{VOKAL+KONSONANT (VC)}

Nê heceyî vokalêk û konsonantêk ra teşekul kenê. Taybetmendîyê bingeyîn yê nê heceyan serê çekuyan de ca girewtiş o (Baskakov, 2006, 194). Qaso ke ameyo tesbîtkerdiş zazakî de bi vokalê /u/ ya tena çekuya uca esta; vokalê /û/ tena halê bestoxî de xoserî nusîyêno; vokalê /i/ zî halê vurîyayîşê vengan de eşkeno sereyê çekuye de ca bigîro. Nê vokalî sereyê çekuyanê xerîban de û sayeyê hedîseyê vengan a eşkenê onset de ca bigîrê. Nê tewir heceyan de vokal û konsonantî pê peya yenê, pê taqîb kenê. Heceyê; $\boldsymbol{a}$ ş, $\boldsymbol{a} \boldsymbol{j}$ - $n e, \boldsymbol{a} \boldsymbol{a}$-qî, $\boldsymbol{e y}$-ne, er-dî-şe, en-teg-re, $\hat{\boldsymbol{e}} \boldsymbol{r}$-xat, îm-kan, în-san, ok-tob-re, uc-ret, ul-ser, $\hat{\boldsymbol{u}} \boldsymbol{m}$ - nê tewir heceyan ra nimûne benê (Grûba Xebate ya Vateyî, 2019). 


\subsubsection{KONSONANT+VOKAL (CV)}

Konsonant û vokal pîya nê tewir heceyî yenê meydan. Mîyanê çekuyan de vokal û konsonantê ke onset, nucleus û coda de eşkenê ca bigîrê, bînayê nê heceyan de zî ca gênê (Baskakov, 2006, 195). Eke heceyêke bi vokalêk a biqedîyo sey heceya akerdê yena namekerdene. No tewir awanîyê heceyan sey heceya sade zî yenê namekerdene (Dizeyî-Heme, 2015, 141). Heceya akerda kurdkî de zaf kêm a. Heta vokalê /i/ û /u/ peynîya hece de sey îstîsna ca gênê (Bedirxan\&Lescot, 2009, 39). Zazakî de nimûneyê heceya akerdê cêr ra deyayê: be-lî, bi-ra-rî, co-ka, ç̂े-yêk, de-ba-re, fî-yet, gi-rek, he-dî-se, ke-man, lo-de, ma-lê-ze, nê-meda-rî, pa-paz, qa-sid, rê-zi-le, se-ma-wer, şu-şe, tê-mî-yan, va-te-ne, wa-yîtrî, xe-ter, ye-waş, zî̀-ret (Grûba Xebate ya Vateyî, 2019).

\subsubsection{KONSONANT+VOKAL+ KONSONANT (CVC)}

Nê tewir heceyî mabênê di hebî konsonantan de ca girewtişê vokalêk reyde yenê meydan. Na hece sey yewine-heceya bingeyine yena qebulkerdene. Îngilîzkî de pergalê heceyan de CVC (konsonant, vokal, konsonant) sey heceya îdeale; C: onset, V: nucleus û C: coda yeno namekerdene. No şekilê heceyan heme cayê çekuyan de eşkeno bibo (Baskakov, 2006, 196). Zazakî de zî nê tewir heceyî zaf vilayê. Nimûneyê nê heceyan: a-zot, ba-jar, ceh-de, ça-pik, der-wês, en-tîk-roş, fît-zîk, gub-re, he-def, î-nad, kar, lê-min, mende, niş-ka, pan-ce, qa-şik, re-qas, sex-tî-yan, şel-xem, têr-can, vaş, war, xem-gîn, xo-pay, yew-fek, za-yîş (Grûba Xebate ya Vateyî, 2019).

\subsubsection{VOKAL+ KONSONANT+ KONSONANT (VCC)}

Nê tewir heceyî vokal û di konsonantan ra pê yenê. Badê vokalî di hebî konsonantî pê peya yenê. Nê tewir bînayê heceyan, zafane çekuyanê ziwananê xerîban ra û xususen zî çekuyê ke erebkî ra derbasê zazakî

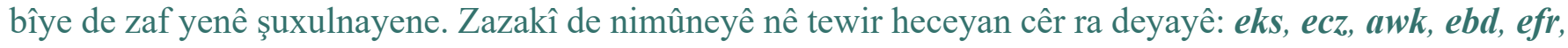
ekr, eks-pert, eks-pres-yon, eks-trem, ens-tî-tu, erd, erd-nas, eyb, ilm, imş, îlm, îzn, oşt, owr, uzr, ors, urs (Grûba Xebate ya Vateyî, 2019).

\subsubsection{KONSONANT+VOKAL+ KONSONANT+ KONSONANT (CVCC)}

$\mathrm{Na}$ hece sere de konsonantêk, dima vokalêk û badê vokalî di hebî konsonantan ra pê yena. Nê tewir heceyî zafane verheceyê çekuyan de ca gênê (Baskakov, 2006, 197). Ne heceyî zazakî de zêde ca nêgênê. Ferhengê ke terefê Grûba Xebate ya Vateyî ra amade bîyê de nimûneyê na hece: bars, bask, bawk, bayt, behd, bejn, berz, bend, best, bext, betl, birr, borr, cehş, çend, çeng, çerm, çerx, deng, derg, dest, dewr, derd, dost, duşt, fehm, ferq, fi-reng, germ, harr, hend, heps, hewt, heşt, heyf, hewş, hukm, huşk, jehr, kerg, kixs, klor, kund, meşk, nehs, panc, penc, pind, pist, qorç, reml, roşn, serd, seyd, Swêd, tehm, terk, teşt, teng, teyr, verg, veng, vezd, wext, wuşk, zehr, zerd, zirç (Grûba Xebate ya Vateyî, 2019).

\subsubsection{KONSONANT+ KONSONANT+VOKAL+ KONSONANT (CCVC)}

No şekil bînayê heceyan zazakî de vila nîyo. Zazakî de nimûneyê ke estê badê vurîyayîşê venganê /û/ > /w/yî vejîyayê meydan. Nimûneyê ke zazakî de estê tena çend hebî yê gweş, gwîn, gwil (Grûba Xebate ya Vateyî, 2016) û seke îfade bî, nê nimûneyî zî badê vurîyayîşê çekuyan vejîyayê meydan û mintiqayêka zaf tenge de yenê vatene. 


\subsubsection{KONSONANT+ KONSONANT+ VOKAL+ KONSONANT+ KONSONANT (CCVCC)}

No şekil bînayê heceyan zazakî de vila nîyo. Zazakî de nimûneyê ke estê badê vurîyayîşê venganê /û/ $>$ /w/yî vejîyênê meydan. Nimûneyê ke zazakî de estê tena çend hebî yê gweşt, gwend (Grûba Xebate ya Vateyî, 2016) û seke îfade bî, nê nimûneyî zî badê vurîyayîşê çekuyan vejîyayê meydan û mintiqayêka zaf tenge de yenê vatene.

\subsubsection{KONSONANT+ VOKAL+ KONSONANT+ KONSONANT+ KONSONANT (CVCCC)}

No şekil bînayê heceyan zazakî de vila nîyo. Zazakî de nimûneyê ke estê badê vurîyayîşê venganê /û/ > /w/yî vejîyênê meydan. Nimûneyê ke zazakî de estê tena çend hebî yê tekst, heyşt (Grûba Xebate ya Vateyî, 2016) û seke îfade bî, nê nimûneyî zî badê vurîyayîşê ç̧ekuyan vejîyayê meydan. Heta kes eşkeno vajo ke çekuyanê xerîban de nê tewir heceyî estê. Nê heceyî hem hece hem zî çekuyan îfade kenê.

\subsection{TEORÎYÊ HECEYAN}

Mijarê ke bi heceyan reyde eleqedarê ra yew zî teorîyê heceyan ê. Analîzkerdiş û nirxnayîşê heceyan de di hebî teorîyê bingeyinî estê. Nê teorî namekerdişê heceyan de yenê şuxulnayene. Heceyî de çi wext û kotî ra bêrê derbkerdiş, taybetmendîyê pêlê ke heceyan, taybetmendîyê umûmî yê heceyan ancax bi teorîyanê heceyan reyde yenê fehmkerdene.

\subsubsection{SONORITY TEORÎ}

Nê teorîyan ra yewine Sonority Teorî ya. Na teorî de goreyê lerzîyayîşê venganê vokalan û konsonantan, heceyî yenê nirxnayena. Eke artîkulasyonê vengêk sewbîna vengan ra cîya bo, no sey sonority yeno namekerdene. Heceyêke de eke vokal bibo, lerzîyayîşê hece nê vengê vokalî ser o yo. Seke yeno zanayene kurdkî de û xususen zazakî de heceyanê yew vokalinan de derb her tim vokalî ser o yo. Heceyêke de yew hebî ra zêde vokal bîyayîş, yew ra zêde hece bîyayîşî rê îşaret keno. Yanî sey yewine-hece, her hece de tena yew heb vokal eşkeno ca bigîro. Eke mîyanê çekuyêke de yew hebî ra zêde vokalî ca bigîrê, kamcîn vokal do bêro derbkrdiş goreyê tayê qaydeyan yeno tesbîtkerdene (Kirkan, 2019, 84-92). Tena vengê vokalî ney, heman şekil de vengê konsonantî zî ge gane taybetmendîyê lerzîyayîşî yanî sonority xo de hewênenê. Hece de yan çekuye de cayê venganê vokalan yan konsonantan lerzîyayîşî yanî sonority tayîn keno.

Kurdkî de vengî sey lerzokî û bêlerzî di tewirî yê. Nê di cureyî zî konsonant ê, çunke vokalî xora lerzok ê. Tîya de lerzayîş ra qesd têlê vengî yê. Artîkulasyonê venganê bêlerzan de têlê vengî nêlerzenê; artîkulasyonê venganê lerzokan de têlê vengî lerzene. Cêr ra vengê konsonantê lerzokî û bêlerzî tablo de ameyê dayene. Nê tabloyî de allofonê nê vengan nêameyê ramojnayene (Muhammed, bêtarîx, 52-55).

Tablo 3: Zazakî de Vengê Konsonantê Lerzok û Bêlerz

\begin{tabular}{|c|c|c|c|c|c|c|c|c|}
\hline Bêlerz & ç & $\mathrm{f}$ & $\mathrm{k}$ & $\mathrm{p}$ & $\mathrm{s}$ & Ş & $\mathrm{t}$ & $\mathrm{x}$ \\
\hline Lerzok & $\mathrm{c}$ & $\mathrm{v}$ & $\mathrm{g}$ & $\mathrm{b}$ & $\mathrm{z}$ & $\mathrm{j}$ & $\mathrm{d}$ & $\ddot{\mathrm{x}}$ \\
\hline
\end{tabular}

Cêr ra vengê lerzokî û bêlerzî ameyê dayene. Vengê lerzokî (titreşimli) goreyê venganê bêlerzan (titreşimsiz) hîna zêde yenê lerzayene. Vengê vokalî goreyê venganê konsonantan hîna zêde yenê lerzayene. Venganê vokalan ra vengê dergî, goreyê venganê kilman hîna zêde lerzene. Vengê ke nêzdîyê venganê lerzokinan ê, goreyê venganê bînan hîna zêde yenê lerzayene (Omar Mahmoud, 2016, 166-167).

Mabênê venganê lerzokan û bêlerzan de eleqeyêk peyda beno û no eleqe hedîseyanê vengan rê bingeyêk amade keno. Cêr ra goreyê na teorî vengê lerzokî û bêlerzî ameyê ramojnayene. Asta lerzîyayîşî cor ra vera cêr kêm bena. Vengê ke tewr cor ra yê tewr zêde yenê lerzayene. Goreyê ney zazakî de vengê tewr lerzokî vengê vokalî yê. 
Tablo 4: Goreyê Teorîya Sonority Zazakî de Asta Lerzîyayîşê Vengan

Zêde

Vokal /a/,/e/,/o/, /u/, /e/, /î/, /i/, /û/

Semî-vokal /w/, /y/

$\mathrm{Nazal} / \mathrm{m} /, / \mathrm{n} /$

Lerzok /1/, /r/

Lateral (kîştî) /l1ł/

Fîzekî /f/, /s/, /ş/, /v/, /z/, /j/, /c/

Teqînayeyî /b/,/c/, /d/, /p/,/t/, /k/,/ç/ Kêm

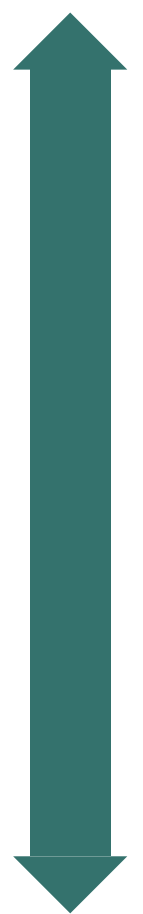

\subsubsection{FONOTAKTÎK TEORÎ}

Manakerdiş û analîzkerdişê heceyan de teorîya dîyine Fonotaktîk Teorî ya. Na teorî herfan, mîyanê heceyan de goreyê rêzebîyayîşî tedqîq kena. Heceyê ke yew vokalî ra pê yenê yew heceyinî, heceyê ke di hebî vokalan ra pê yenê di heceyinî ûsn. yenê dabeşkerdene. Goreyê na teorî, eke vokalêk heceyêke de mabênê di hebî konsonantan de ca bigîro, na hece vokalêkê bînî reyde heceyêka newê saz bikero, konsonantê peynî beno elemanê heceya dîyine. Vurîyayîşe çekuya Reng $+\hat{\imath} n=\operatorname{Ren}+$ gîn kes eşkeno sey nimûne bido.

Teorîya fonotaktîke de heceyî di şekilan a yenê analîzkerdene. Nînan ra verênê ci rastekê tîkane (hierarchical structure), dîyine rastekê ufuqî (linear structur, $\boldsymbol{\sigma}$ şekilê sîgmayî de) yo. Pergalê CVCyî de onset cîya yeno namekerdene, labelê nucleus û coda sey rhyme (qetab, kafiye, uyak) yenê namekerdene. Hece de muhîm nucleus o, coda û onset seba awanbîyayîşê heceyî mecburî nîyê.

\section{Şekil 1: Goreyê Teorîya Fonotaktîkî Zazakî de Modelê Heceyan}

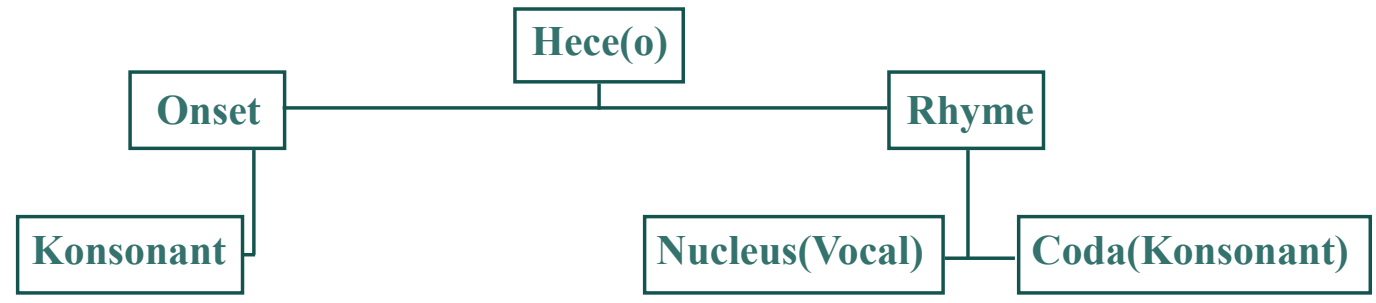

Cêr ra tablo de goreyê teorîya fonotaktîkî, heceyê zazakî ameyê analîzkerdene. Cor ra derheqê babetanê heceyan de melumatî deyayîbî. Tîya de goreyê babetanê heceyan wayîrê onset û coda bîyayîşî teqsîmatêk ameyokerdene. Seke verê cû zî amebî vatene, hece de bingeh nucleus o, yanî vokal o. Eke vokal nêbo hece nêyena sazkerdene. Coda û onset seba awanîya heceyan mecburî nîyê. Labelê seke cêr ra zî aseno, mîyanê heceyan de onset û codayî eşkenê yew heb ra zêde konsonantan ra zî pê bêrê. 
Tablo 5: Analîzê Fonotaktîkê Heceyanê Zazakî

\begin{tabular}{|l|l|l|l|l|}
\hline & Hece & Onset & Nucleus & Coda \\
\hline V & {$[\mathrm{a}]$} & {$[-]$} & {$[\mathrm{a}]$} & {$[-]$} \\
\hline VC & {$[-\mathrm{en}]$} & {$[-]$} & {$[\mathrm{e}]$} & {$[\mathrm{n}]$} \\
\hline CVC & {$[$ te- $]$} & {$[\mathrm{t}]$} & {$[\mathrm{e}]$} & {$[-]$} \\
\hline VCC & {$[$ gub- $]$} & {$[\mathrm{g}]$} & {$[\mathrm{u}]$} & {$[\mathrm{b}]$} \\
\hline CVCC & {$[$ eyb] } & {$[-]$} & {$[\mathrm{e}]$} & {$[\mathrm{yb}]$} \\
\hline CCVC & {$[$ dost $]$} & {$[\mathrm{d}]$} & {$[\mathrm{o}]$} & {$[\mathrm{st}]$} \\
\hline CCVCC & {$[$ gwîn $]$} & {$[\mathrm{gw}]$} & {$[\hat{\mathrm{i}}]$} & {$[\mathrm{n}]$} \\
\hline CVCCC & {$[$ gweşt $]$} & {$[\mathrm{gw}]$} & {$[\mathrm{e}]$} & {$[$ şt $]$} \\
\hline
\end{tabular}

\subsection{HÛMARÊ HECEYAN}

Çekuyê ke zazakî de ca gênê eşkenê yew heceyin, di heceyin, hîrê heceyin, çar heceyin, panc heceyin û şeş heceyin bibê. Heceyî goreyê vokalan yenê namekerdene. Heceya ke tede tena yew heb vokal esto yew heceyin; heceyê ke tede şeş hebî vokalî estê zî şeş heceyin yena qebulkerdene. Zêdebîyayîşê hûmarê heceyan, mabênê heceyan de meseleya derbî vejena meydan. Çekuyanê yew heceyinan de derb her tim vokalî ser o yo. Labelê çekuyanê zaf heceyinan de vokalî zaf ê, o semed ra derb eşkeno cîya cayan de çekuye de bibo. Çekuye de zaf vokalî bibê, ganî nê vengan ra hebêk yan çend hebî bêrê derbkerdene. Derheqê zazakî de derbî de terefê ma ra nuşteyêk ameyo nuştene (Kirkan, 2020). Qandê cû derheqê derbî de tîya de zêde agahî nêdeyayê. Her hece de çend hebî konsonantî eşkenê bibê. Cêr ra goreyê vokalanê zazakî hûmarê heceyan tablo de ameyê îzahkerdene.

Tablo 6: Zazakî de Çekuyî û Hûmarê Heceyan

\begin{tabular}{|l|l|l|l|l|l|}
\hline & & & & \\
& & & & & \\
\end{tabular}




\section{ENCAM}

Na xebate de babetê heceyanê zazakî ameyo tedqîqkerdene. Sey ziwananê bînan zazakî de zî heceyî vokalan reyde yenê awankerdene. Heceyî goreyê rêzebîyayîş vokalan û konsonantanê xo yenê namekerdene. $\mathrm{Na}$ xebate de heceyê zazakî goreyê teorîyanê heceyan ameyê analîzkerdene. Nê teorîyan ra teorîya fonotaktîke de babetê heceyan, goreyê rêzebîyayîşê heceyan ameyo tehlîlkerdene. Goreyê ney zazakî de, herçiqas tayê babetê heceyan zêde nêrê şuxulnayîş zî, 9 babetî heceyî estê. Nê heceyan ra tayê ci mîyanê ziwanî de, çi fekkî çi nuştekî, zêde yenê şuxulnayene; tayê ci zî hetê nîsbetî ra kêm manenê.

Teorîya dîyine ya heceyan teorîya sonority ya. Goreyê na teorî ziwanan de vengê lerzokî û bêlerzî estê. Vengê lerzokî goreyê lerzîyayîșê têlanê vengî yenê tesbîtkerdene. Vengê ke artîkulasyon de têlanê vengî lerznenê sey vengê lerzokî; vengê ke artîkulasyon de têlanê vengî nêlerznenê sey vengê bêlerzî yenê namekerdene. Goreyê ma bingeyê hedîseyanê vengan (cavurînayîşê, bedilîyayîş û kêm-zêdebîyayîş) teorîya sonority ya. Çunke goreyê na teorî vengî lerzenê û yewbînan ser o tesîr kenê. Nê tesîrî reyde vengî, nêzdîyê yewbînan benê û vurîyênê. Heme ziwanan de vengê vokalî, lerzok ê. Hetê lerzîyayîşî ra mabênê venganê konsonantan de rewşêka tedrîcî esta. Na xebate de goreyê lerzîyayîşê vengan taybetmendî ameyê mojnayene.

Meseleyêka bîne hecekerdişê çekuyan o. Hecekerdiş ge gane mîyanê çekuyan de tewlîhewîyêk ano meydan. Peynîya satirî de çekuyê pêrabesteyî cîya cîya nêyenê hecekerdene. Sernameyê nuşteyan de çekuyî nêyenê hecekerdene. Nameyê taybetî nêyenê hecekerdene. Tarîxî de û hûmarî nêyenê hecekerdene. Kilmnusan de çekuyê ke bi şekilêko kilm nusîyayê nêyenê hecekerdene. Çekuyê yew heceyinî reyna nêyenê hecekerdene. Nuştişê adresê keyepelan de û e-postayan de nameyî nêyenê hecekerdene.

Na xebate de heceyê zazakî ameyê îzahkerdene û seba her babetê hece ferhengan ra nimûneyî deyayê. Seba nimûneyan kitaban ra îstîfade nêbîyo. Çunke mînakê tayê heceyan kitaban de nêyenê tesbîtkerdene. Kitabî zafane goreyê ziwanê standardî ameyê amadekerdene û taybetmendîyanê fekan nêdanê. 


\section{çimeYî}

Aksan, Doğan. Her Yönüyle Dil, Ana Çizgileriyle Dilbilim. Ankara: Türk Dil Kurumu, 2015.

Aktuğ, Halil. Gramera Kurdî/Kürtçe Gramer. İstanbul: Avesta, 2013.

Baskakov, N. A. Türk Dillerinde Tarihi-Tipolojik Sesbilimi. İstanbul: Multilingual, 2006.

Bayraktar, Nesrin. Dilbilim. Ankara: Nobel, 2014.

Bedirxan Celadet Alî, Lescot, Roger. Kürtçe Gramer. İstanbul: Avesta, 2009.

Bussman, H. Routledge Dictionary of Language and Linguistics. New York: Routledge, 1998.

Crystal, D. A Dictionary of Linguistics and Phonetics. Oxford: Blackwell, 2008.

Demirci, Kerim. Türkoloji İçin Dilbilim Konular Kavramlar ve Teoriler. Ankara: Anı Yayınc1lık, 2014.

Dizeyî Ebdulwahîd Muşîr, Heme Dana Tehsîn ûêb. Fonetîk û Fonolocî. Hewlêr: Çapxaney Hêvî, 2015.

Grûba Xebate ya Vateyî. Ferhengê Kirmanckî Zazakî- Tirkî Kırmancca Zazaca-Türkçe Sözlük. İstanbul: Vate, 2016.

Grûba Xebate ya Vateyî. Sözlük Türkçe-Kırmancca Zazaca. Ferhengê Tirkî-Kirmanckî. İstanbul: Vate, 2019.

Hengirmen, Mehmet. Dilbilgisi ve Dilbilim Terimleri Sözlüğü. Ankara: Engin Yayınevi, 2009.

Husein Muhammed. Dengnasî di Kurdî de. Weşano Dîjîtal. Adres: https://zimannas.files.wordpress.com/2016/08/dengnasi1.pdf

Karaağaç, Günay. Dil Bilimi Terimleri Sözlüğü. Ankara: Türk Dil Kurumu, 2013.

Karaağaç, Günay. Türkçenin Ses Bilgisi. İstanbul: Kesit, 2018.

Kırkan, Ahmet. Zazacanın Fonetik Açıdan İncelenmesi; Kuzey, Güney ve Merkez Zazacasının Karşılaştırılması. Tezê Doktorayê Çapnêbîyaye, Diyarbakır: Dicle Üniversitesi Sosyal Bilimler Enstitüsü, 2019.

Komxebata Kurmancîyê. Rêbera Rastnivîsînê. Dîyarbekir: Weqfa Mezopotamyayê, 2019.

Korkmaz, Zeynep. Gramer Terimleri Sözlü̆̈̈̈. Ankara: Türk Dil Kurumu, 1992.

Malmîsanij, Mehemed. Ji Bo Rastnivîsînê Ferhenga Kurdî Kurmancî-Tirkî. İstanbul: Rûpel, 2012.

Omar Mahmoud, B. Şîrovekirineke Dengsazî û Fonolojî di Kurdiya Kurmancî de. Mêrdîn: Zanîngeha Mardîn Artukluyê Enstîtuya Zimanên Zindî yên li Tirkiyeyê Teza Masterî ya Neçapkirî, 2016.

Saussure, Ferdinand de. Genel Dilbilim Yazıları. İstanbul: İthaki, 2014.

Tan, Sami. Rêziman û Rastnivîsa Zaravayê Kurmancî. İstanbul: Enstîtuya Kurdî ya Stenbolê, 2011.

Vardar, B. Ed.. Açıklamalı Dilbilim Terimleri Sözlüğü. İstanbul: Multilingual, 2002. 


\section{EXTENDED ABSTRACT}

While the items in the language are subjected to examination, they are divided into certain parts according to their characteristics and examined in this way. There are segmental and suprasegmental elements in each language. Segmental elements consist of vocal, consonant, phoneme, allophone, morpheme and allomorphs. Elements found at the segmental level do not have semantic features and represent physiological features of language. Apart from the segmental level, there are also items found at the suprasegmental level in the tongue. The elements found at the suprasegmental level determine the meaning character of the language and these elements represent the social aspect of the language. Elements at the suprasegmental level consist of elements such as stress, tone, melody, pause, velocity and syllable, and these elements are generally shaped according to the wishes and needs of the speaker. Syllables, on the other hand, are one of the special structures in language and are usually the language element that provides the link between the meaning and form features of the language. Although there are consonant sounds, syllables are made up of vocal sounds and the syllable numbers of words are determined according to the number of vocal sounds. There can be only one vocal sound in a syllable, increasing the number of vocal leads to the emergence of different syllables. Vocal sounds in the word determine the number of syllables. In this study, syllable types in Zazaki were analyzed. The syllables in Zazaki are classified in different ways according to the characteristics of vocal and consonant sounds. According to the naming of the consonant (C) and vocal (V) sounds in English, the ideal syllable is called CVC. In this syllable, the first sound is called the initial consonant onset, the vocal sound is called nucleus, and the final condonant is called the coda. The aim of this study is to divide the syllables in Zazaki according to the distribution of vocal and condonant sounds, to determine the sounds in the coda and onset of the words, and to analyze the characteristics of the syllables in Zazaki according to the characteristics of these sounds. In the study, other syllables were expressed according to this ideal syllable. With the decrease of coda and onsette vocal voices, geminate condonant sounds occur. Although there are syllables that are geminate concentric in Zazaki, syllables with diphthong sounds are not included in the standardized written language. However, diphthong sounds and diphthong syllables are actively and widely used in some regions where Zazaki is spoken, such as the Bingol dialect. The syllables containing geminate condonants, which are formed by lowering vocal sounds, were first identified in this study and classified according to the presence of geminate condonant sounds at the beginning or at the end, and these syllables are shown in the table. Diphthongs and geminate condonants in some dialects of zazaki are not regarded as independent 
syllables and the hinterland of these syllables is not wide. While explaining syllable types in the study, these factors can be determined easily. In the study, examples of texts written in Zazaki were brought and syllables were concretized in this way. Some examples of syllables mentioned in the study are given only from a few words. Examples of these syllables are the syllables that generally exist in the Bingöl dialect. As far as it is determined, Bingöl dialect has a wide and rich vocabulary in terms of oral literature and folkloric materials. Because syllables made up of diphthongs and geminate condonants were detected only in this region. In some regions, such as Siverek and its surroundings, where Zazaki is spoken, it can be said that the spoken language is closer to the standard writing. Explanation and sampling are used as methods in this study, and the explanations are supported with examples from the texts. In addition, the syllables found in $\mathrm{Za}-$ zaki were examined in terms of phonotactic theory and sonority theory, and the values of syllables were examined according to these two theories. In the study, it was determined that the sound and meaning features of syllables in Zazaki are in harmony with other dialects of Kurdish. It is hoped that the results obtained in the study will form a basis for phonological studies on suprasegmental elements. Comparative linguistic studies to be carried out between the regions where Zazaki is spoken is important in terms of determining the hidden features of Zazaki. The framework of the study is limited to syllable and syllable types. 